\title{
Animation et culture scientifique et technique : l'observatoire astroamateur de Narbonne
}

\section{J. Cazenove}

\section{(2) OpenEdition}

1 Journals

Édition électronique

URL : http://journals.openedition.org/trema/2362

DOI : 10.4000/trema.2362

ISSN : 2107-0997

Éditeur

Faculté d'Éducation de l'université de Montpellier

\section{Édition imprimée}

Date de publication : 1 mai 1993

Pagination : 115-116

ISSN : 1167-315X

\section{Référence électronique}

J. Cazenove, «Animation et culture scientifique et technique : l'observatoire astroamateur de

Narbonne », Tréma [En ligne], 3-4 | 1993, mis en ligne le 01 mai 1993, consulté le 20 avril 2019. URL

http://journals.openedition.org/trema/2362 ; DOI : 10.4000/trema.2362

Ce document a été généré automatiquement le 20 avril 2019.

Trema 


\title{
Animation et culture scientifique et technique : l'observatoire astroamateur de Narbonne
}

\author{
J. Cazenove
}

\section{L'astronomie : domaine privilégié}

1 D'une part, l'astronomie permet d'avoir, pour laboratoire, l'univers (corps noir par excellence, on vient juste de le vérifier expérimentalement avec le satellite COBE!). Ceci plait aux jeunes pour évoquer les questions fondamentales qui se posent.

2 D'autre part, l'astronomie exige de «taquiner» tous (ou presque) les domaines de la physique classique ou moderne. On appelle cela l'astrophysique.

\section{Les moyens}

3 Au cours de nos onze années d'aventure scientifique, dans un observatoire que nous avons créé et construit de toutes pièces (local et matériel), par le biais de P.A.E. (Projets d'Action Educative) avec l'aide de l'ANVAR, de la mission d'Action Culturelle du Rectorat de Montpellier, du Foyer Socio-Educatif de la Mairie de Narbonne, du Conseil Régional Languedoc-Roussillon, divers ateliers en services permettent des travaux en :

- astrophotographie avec possibilité d'hypersensibiliser les films,

- imagerie numérique (2 caméras CCD à barrette et matrice),

- spectrométrie et photométrie stellaire,

- radioastronomie sur $144 \mathrm{MHz}$ et $432 \mathrm{MHz}$,

- imagerie satellitaire Météosat / NOAA. 


\section{Les résultats}

- Des publications présentent les résultats obtenus par les différentes équipes qui se succèdent au fil des années. (Les nouvelles recrues de troisième et de seconde, formées par les anciens de terminale poursuivent en général les travaux commencés). Il existe donc une bonne continuité dans nos expériences.

- Des animations proposées aux scolaires (des C.E.S., des foyers ruraux ou Centres de vacances) permettent de vulgariser les acquis théoriques et techniques développés dans notre Observatoire (une moyenne de 30 classes soit 1000 élèves et plus de 500 adultes profitent de ces soirées d'observation chaque année).

- La venue de conférenciers renommés, l'organisation de concerts (Fête de la Musique ou de la Science) et d'expositions suivis d'une soirée d'observation permettent, de plus en plus, d'associer auprès du public la science et les arts.

- La construction récente d'un planétarium de 3,70 $\mathrm{m}$ avec la société narbonnaise INACO a considérablement accru la qualité et l'efficacité de nos interventions. Un spectacle audiovisuel est préparé par une équipe, où l'aspect scientifique se marie très agréablement avec mythologie, poésie et musique!

- Un atelier vidéo science en cours de réalisation permettra cette année la mise en chantier de films d'initiation et vulgarisation à usage interne essentiellement destiné aux publics très divers fréquentant l'Observatoire.

Les ateliers scientifiques proposés par le Rectorat de l'Académie de Montpellier depuis la rentrée 91/92 dans notre Lycée Diderot, et la décharge de service qui m'a été accordée pour la rentrée 92/93 vont bien sûr permettre de développer dans de bien meilleures conditions cette animation culture-science-technique. Des contacts avec divers IUFM ont déjà été pris pour que l'Observatoire de Narbonne devienne un véritable centre de formation dans le domaine de l'enseignement des sciences dans les établissements scolaires. Merci donc aux services du Rectorat qui contribuent à la mise en place de cette culture scientifique et technique. Le retard était grand sur d'autres disciplines (littéraires ou artistiques).

\section{Les exposciences}

5 Les expériences scientifiques se doivent d'être confrontées pour qu'une bonne progression soit assurée. Les exposciences régionales (EINSTEIN à Carcassonne - ESI pour les exposciences internationales) ont le mérite de favoriser ces échanges indispensables auprès des jeunes de cultures et traditions différentes. Notre équipe a participé à ce jour, à toutes les exposciences régionales et internationales. Elle est 12 fois lauréate de grands prix accordés par des jurys spécialisés. Merci donc à tous ceux qui contribuent à l'organisation de ces rencontres entre jeunes (M.A.C. - A.N.S.T.J. - C.I.R.A.S.T.I. - M. G. ANDUZE).

6 Pour toutes visites ou stages, contacter J. Cazenove, Lycée Technique de Narbonne, rue Jean Moulin, BP 828, 11108 Narbonne. 


\section{RÉSUMÉS}

L'Observatoire Astronomique amateur de Narbonne dont nous présentons les principales réalisations est une structure périscolaire permettant aux élèves de faire des Sciences pratiques techniques et culturelles, en dehors de toute contrainte imposée par un programme officiel.

The demands of the official curriculum and the requirements of the scientific method used in the teaching of Physics don't allow us too much latitude in the classroom. Therefore the means to have full discretion to act are to be found in extra-curricular activities dealing with cultural, technical and practical sciences. This is achieved in the Amateur Astronomy Observatory in Narbonne, and this paper presents the main realisations.

\section{INDEX}

Mots-clés : activité périscolaire, astronomie

\section{AUTEUR}

\section{J. CAZENOVE}

Lycée technique de Narbonne 